\title{
Copper(II) Complex Formation with a Poly(amido) Polymer Containing Optically Active $\alpha$-Alanine Residues
}

\author{
Rolando BARbuCCI, Mario Casolaro, and Agnese Magnani \\ Dipartimento di Chimica, Università di Siena, \\ Piano dei Mantellini 44, 53100, Siena, Italy
}

(Received June 2, 1989)

\begin{abstract}
The complex formation between copper(II) and a polyampholyte ligand derived from $\alpha$-alanine and 1,4-bis(acryloyl)piperazine was studied in aqueous solution by both thermodynamic (potentiometry, calorimetry) and spectroscopic (UV-visible, Electronic Spin Resonance, FTinfrared, Circular Dichroism) methods. It was found that a single complex species is formed in the acidic region and its thermodynamic functions $\left(-\Delta G^{\circ},-\Delta H^{\circ}\right.$, and $\left.\Delta S^{\circ}\right)$ were determined. Each monomeric unit of the polymer is involved in the coordination with the $\mathrm{Cu}(\mathrm{II})$ metal ion. Circular dichroism and infrared spectral data clearly reveal the participation of the carbonyl groups of the backbone in the copper(II) complex formation. The optically active center present in the coordinated amino acid residue shows a dissymmetric perturbation since it is involved in a five membered chelate ring fused with one of six members, whatever the $\mathrm{pH}$
\end{abstract}

KEY WORDS Polyampholytes / Chiral Polymers / ESR / FT-IR / Circular

Dichroism / Potentiometry / Calorimetry / Stability Constants / Copper(II)

Complexes /

In previous papers ${ }^{1-4}$ we have reported the study of several examples of copper(II) complexes of basic polyelectrolytes containing different shielding groups, with the aim of rationalizing the complexity arising from the cooperative effects of monomeric units. ${ }^{5}$

Among these, the poly(amido) polymers containing amino acid residues and bis-acryloyl piperazine moiety

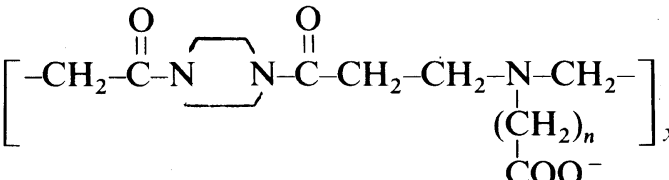

$$
\begin{aligned}
& (n=1) \quad \text { PAAA }_{1} \\
& (n=2) \quad \mathrm{PAAA}_{2}
\end{aligned}
$$

have $\mathrm{Cu}$ (II) stability constants which decrease with $\mathrm{pH}^{2}$ The coordinating properties of the corresponding non-macromolecular models were also investigated by thermodynamic and spectroscopic techniques and the decreasing trend of $\log \beta$ for the $\mathrm{CuL}^{+}$species ( $\mathrm{L}$ means the anionic monomer unit of the polymer) could be entirely attributed to the statistical entropy term. ${ }^{6}$

This paper reports the results of a study of another related optically active polyampholyte derived from 1,4-bis(acryloyl)piperazine with $\alpha$-alanine $\left.(l \text {-PAAA })_{1}\right)^{7}$ :<smiles>CC(=O)C1CCCCN(CCC(=O)N2CCCCC2)C1=O</smiles>

l-PAAA

The protonation behavior of this polymer was previously studied by spectroscopic and thermodynamic techniques with particular attention to conformational transitions. ${ }^{7} \mathrm{We}$ wish now to clarify the copper(II) complex 
formation process of this class of poly(amido) polymers containing amino acid residues, by spectroscopic (Circular Dichroism, FT-IR, E.S.R. UV-vis) and thermodynamic (potentiometry, calorimetry) methods.

\section{EXPERIMENTAL}

Synthesis of Poly(amido- $\alpha$-alanine) (l-PAAA $)$

The polymer was first synthesized ${ }^{7}$ by a Michael-type hydrogen transfer addition utilizing the synthetic 1,4-bis(acryloyl)piperazine ${ }^{8}$ and $l$-alanine (from Merck) products in aqueous solution in the presence of triethylamine.

\section{Spectroscopic Measurements}

Visible absorption spectra were recorded at room temperature in aqueous $0.1 \mathrm{M} \mathrm{NaCl}$ solution at different $\mathrm{pHs}$ with a Perkin-Elmer 320 spectrophotometer using $1-\mathrm{cm}^{3}$ silica cells. The titrations were performed by stepwise addition of $0.1 \mathrm{M}$ sodium hydroxide solution to a known amount of polymer dissolved in $0.1 \mathrm{M} \mathrm{NaCl}(5 \mathrm{ml})$, containing copper(II) in a $\mathrm{Cu}(\mathrm{II}) / \mathrm{L}$ molar ratio of $1:(1-3)$ with a large excess of hydrogen ions. A titration at $\mathrm{pH} 3.5$ was also performed by adding increasing amounts of copper(II) nitrate until $\mathrm{Cu}(\mathrm{II}) / \mathrm{L}$ : $1: 1$ was reached. The $\varepsilon$ value was calculated from the species distribution given by the basic FIT program previously described, ${ }^{9}$ on an Olivetti M28 computer.

Electronic spin resonance measurements were made with a Brucker ER-200 spectrometer at X-band frequencies. Diphenylpicrylhydrazyl (DPPH) was used as field marker. Ethylene glycol was added to the aqueous copper/polymer ligand $(1: 2)$, at measured $\mathrm{pH}$, to improve glass-forming properties at low temperature. The basic computer program used for the simulation of the spectra is a much modified version of a program originally written by Venable. ${ }^{10}$ All simulations were carried out on an Olivetti M20 computer with 128 kbytes of memory.

The FT-infrared spectrum was recorded on a Perkin-Elmer FT-IR spectrometer M1800 between 3000 and $900 \mathrm{~cm}^{-1}$. An MCT detector was used and the apparatus purged with dry nitrogen. Typically 300 scans at a resolution of $2.0 \mathrm{~cm}^{-1}$ were averaged and the spectrum stored on floppy disk. The frequency scale was internally calibrated with a reference $\mathrm{He}-\mathrm{Ne}$ laser to an accuracy of $\pm 0.01 \mathrm{~cm}^{-1}$. A Barnes microcircle cell for liquid with a germanium crystal was used to record the spectrum in the aqueous solution. The concentration of the polymer solution was $0.04 \mathrm{M}$ and the copper(II)/ligand molar ratio was $1.5: 1$ at pH 3.6. A Perkin-Elmer 7500 data station was used to obtain a difference spectrum of the $\mathrm{Cu}$ (II) complex-water system. The water subtraction from the complex solution was made by the null criterion, trying to minimize the water band.

Circular dichroism spectra were recorded at room temperature with a Jasco J-20 spectropolarimeter in the $250-195 \mathrm{~nm}$ wavelength range. The apparatus was flushed with dry nitrogen and a CD fused-quartz optical cell was used throughout $C D$ measurements on the copper(II) complex at various $\mathrm{pHs}$ were carried out by preparing each solution with a known amount of polymer and copper(II) chloride at different molar ratios and adjusting the $\mathrm{pH}$ to the desired value. The copper(II) solution was stepwise delivered by a dispenser microsyringe $(10 \mu \mathrm{l}$ Drummond, $\bmod 210)$ to a polymer solution in $1 \mathrm{~mm}$ fused-quartz optical cell. The spectra were smoothed and solvent subtracted using the CDDPPC program operating on a NEC PC-9801F personal computer. ${ }^{11}$ The molar ellipticity is given by the relation $[\theta]=(100 \times \psi) /(0.1 \times C)$, where $\psi$ is the dichroic optical density in degrees and $C$ $\left(\mathrm{mol} \mathrm{dm}{ }^{-3}\right)$ the concentration of the residue amide groups (two for each monomeric unit).

\section{Potentiometric Measurements}

Potentiometric titrations were carried out according to a previously described procedure. ${ }^{4}$ A digital PHM 84 Radiometer poten- 
Table I. $\mathrm{Cu}(\mathrm{II})$-complex formation: experimental details of the potentiometric and calorimetric measurements of $l$-PAAA 1 in $0.1 \mathrm{M} \mathrm{NaCl}$

\begin{tabular}{|c|c|c|c|c|c|c|}
\hline$T_{\mathrm{L}} / \mathrm{mmol}^{\mathrm{a}}$ & $T_{\mathrm{M}} / \mathrm{mmol}^{\mathrm{a}}$ & $T_{\mathrm{H}}+/ \mathrm{mmol}^{\mathrm{a}}$ & $C_{\mathrm{T}} / \mathrm{mol} \mathrm{dm}^{-3 \mathrm{a}}$ & pH-range & Points ${ }^{b}$ & \\
\hline & & & Potentiometry & & & \\
\hline 0.1991 & 0.1593 & 0.8429 & 0.0756 & $2.27-5.14$ & 103 & \\
\hline 0.1813 & 0.0918 & 0.8990 & 0.0756 & $2.26-5.13$ & 103 & \\
\hline \multirow[t]{2}{*}{0.1889} & 0.1163 & 0.8519 & 0.0756 & $2.28-5.05$ & 85 & \\
\hline & & & Calorimetry & & & $\begin{array}{c}-\Delta H^{\circ \mathrm{d}} \\
\mathrm{kcal} \mathrm{mol}^{-1}\end{array}$ \\
\hline 0.2131 & 0.2195 & 0.3040 & 0.1265 & $2.38-4.97$ & 42 & $5.4(3)$ \\
\hline 0.1712 & 0.1326 & 0.2889 & 0.1265 & $2.46-5.96$ & 32 & $6.1(4)$ \\
\hline \multirow[t]{2}{*}{0.2061} & 0.0000 & 0.2061 & $0.1087^{\mathrm{c}}$ & $3.15-2.40$ & 47 & $6.3(2)$ \\
\hline & & & & & Average & $5.9(5)$ \\
\hline
\end{tabular}

a $T_{\mathrm{L}}=$ initial quantity of ligand; $T_{\mathrm{M}}=$ initial quantity of copper(II) ions; $T_{\mathrm{H}}+=$ initial quantity of hydrogen ions;

$C_{\mathrm{T}}=$ sodium hydroxide titrant conc.

b Number of points from titration curve.

c Copper(II) titrant conc.

d Values in parentheses are standard deviations.

tiometer was used together with a Ross reference electrode $(\bmod 80-05)$ and a Ross glass electrode $(\bmod 81-01)$ immersed in the aqueous solution in a constant-temperature cell at $25^{\circ} \mathrm{C}$. Presaturated nitrogen was kept over the surface of the solution to prevent carbon-dioxide contamination. The formation constant of the $\mathrm{Cu}(\mathrm{II})$-polymer system was determined by adding standard sodium hydroxide solution to an acidic solution containing several different molar ratios of polymer to copper(II) nitrate. All solutions were prepared immediately before use. Three independent titrations were performed and the experimental details are summarized in Table I. The potentiometric and titration apparatus was automatically controlled by an Olivetti M20 computer. The stability constant was computed for each titration point using the basic SUPERFIT program previously described. ${ }^{2}$

\section{Calorimetric Measurements}

Continuous calorimetric titrations were carried out at $25^{\circ} \mathrm{C}$ with a Tronac 1250 calorimeter by a previously reported procedure, ${ }^{9}$ operating in the Isothermal mode. The com- plex formation enthalpy was determined by adding standard sodium hydroxide solution to an acidic copper(II)-polymer solution contained in a $25-\mathrm{cm}^{3}$ stainless-steel reaction vessel. A titration of the polymer solution as such was performed with copper(II) nitrate solution until a $\mathrm{Cu}(\mathrm{II}) / \mathrm{L}$ molar ratio of $1: 1$ was achieved. Table I summarizes the experimental details of the calorimetric measurements. The $-\Delta H^{\circ}$ values, corrected for the heats of dilution of the titrant, were calculated using the FIT program ${ }^{9}$ on an Olivetti M24 computer.

\section{RESULTS}

The l-PAAA 1 polymer formed only one stable complex with copper(II) ions in the acidic region.

Spectroscopic (ESR and UV-vis) measurements were first carried out at different $\mathrm{pHs}$ to identify the species formed in the $\mathrm{Cu}(\mathrm{II}) /(\mathrm{l}$ PAAA $_{1}$ ) system. The ESR spectra recorded at low temperature $(77 \mathrm{~K})$ were indicative of the presence of a single complex species (Figure 1). The ESR parameters did not change with $\mathrm{pH}$ 


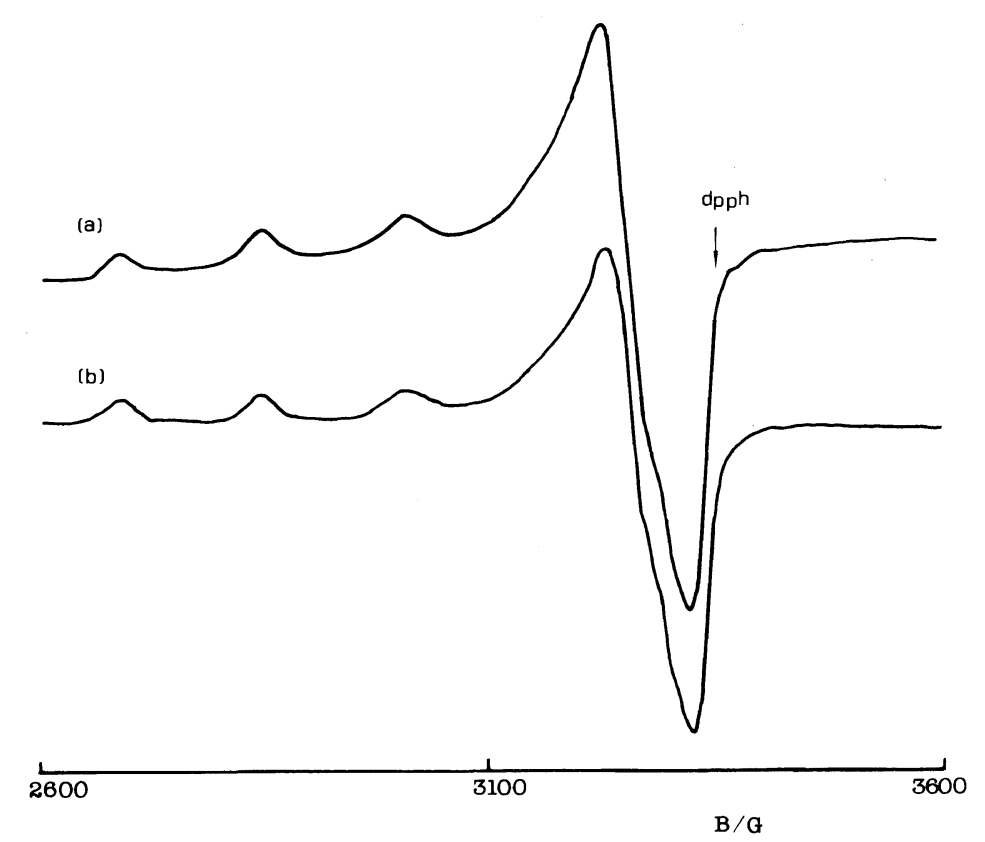

Figure 1. ESR spectra of a 2/1: (l-PAAA $) / \mathrm{Cu}(\mathrm{II})$ aqueous solutions at $77 \mathrm{~K}$ and at different $\mathrm{pHs}[(\mathrm{a})$ pH 2.6, (b) $\mathrm{pH} 4.4]$.

Table II. ESR and electronic spectral data for the copper(II) complex species of $l$-PAAA 1 and related $\mathrm{PAAA}_{n}$ polymers ${ }^{\mathrm{a}}$

\begin{tabular}{lcccccc}
\hline Complex species & $g_{\|}$ & $g_{\perp}$ & $10^{4} A_{\|} / \mathrm{cm}^{-1}$ & $10^{4} A_{\perp} / \mathrm{cm}^{-1}$ & $\frac{\lambda_{\text {max }} / \mathrm{KK}}{\varepsilon / \mathrm{dm}^{3} \mathrm{~mol}^{-1} \mathrm{~cm}^{-1}}$ & Ref \\
\hline $\mathrm{Cu}(l$-PAAA & & & $13.8(94)$ & This paper \\
$\mathrm{Cu}\left(\mathrm{PAAA}_{1}\right)^{+}$ & 2.298 & 2.058 & 162.0 & 14.0 & $13.6(32)$ & 6 \\
$\mathrm{Cu}\left(\mathrm{PAAA}_{2}\right)^{+}$ & 2.335 & 2.080 & 177.7 & 10.7 & $13.4(53)$ & 6 \\
\hline
\end{tabular}

a $l$-PAAA ${ }_{1}=$ poly $($ amido- $\alpha$-alanine $) ;$ PAAA $_{1}=$ poly (amido-glycine); PAAA $_{2}=$ poly $($ amido- $\beta$-alanine $)$.

in the $2.6-4.4 \mathrm{pH}$ range and are reported in Table II together with the electronic spectral data. The $g_{\|}$value was lower than for previous comparable $\mathrm{Cu}$ (II)-complexes with poly(amido) polymer containing glycine (PAAA ${ }_{1}$ ) or $\beta$-alanine $\left(\mathrm{PAAA}_{2}\right)$ residues as ligand. ${ }^{6}$ In the visible range the absorption spectra of $\mathrm{Cu}(\mathrm{II}) /\left(l\right.$-PAAA $\left.\mathrm{PA}_{1}\right)$ showed no shift in the wavelength of the $d-d$ transition of copper(II) when $\mathrm{pH}$ was increased from 1.7 to 5.4 , suggesting that only a single complex species was present in solution. The spectrum was typical of a $1: 1 \mathrm{Cu}(\mathrm{II}) / \mathrm{L}$ complex involving both amino nitrogen and carboxylate groups, ${ }^{12}$ but the absorption maxima of the $\mathrm{Cu}(\mathrm{II})$ complex occurred at a shorter wavelength compared to the homologous $\mathrm{Cu}\left(\mathrm{PAAA}_{n}\right)^{+}$ $(n=1,2)$ systems. The low values of the ESR parameters and the spectral shift to high energy might be explained by a different geometric arrangement of the coordinating groups of $l$-PAAA $A_{1}$ around the copper(II) ion, unlike the octahedral tetragonallydistorted structure shown for PAAA $_{1}$ and 

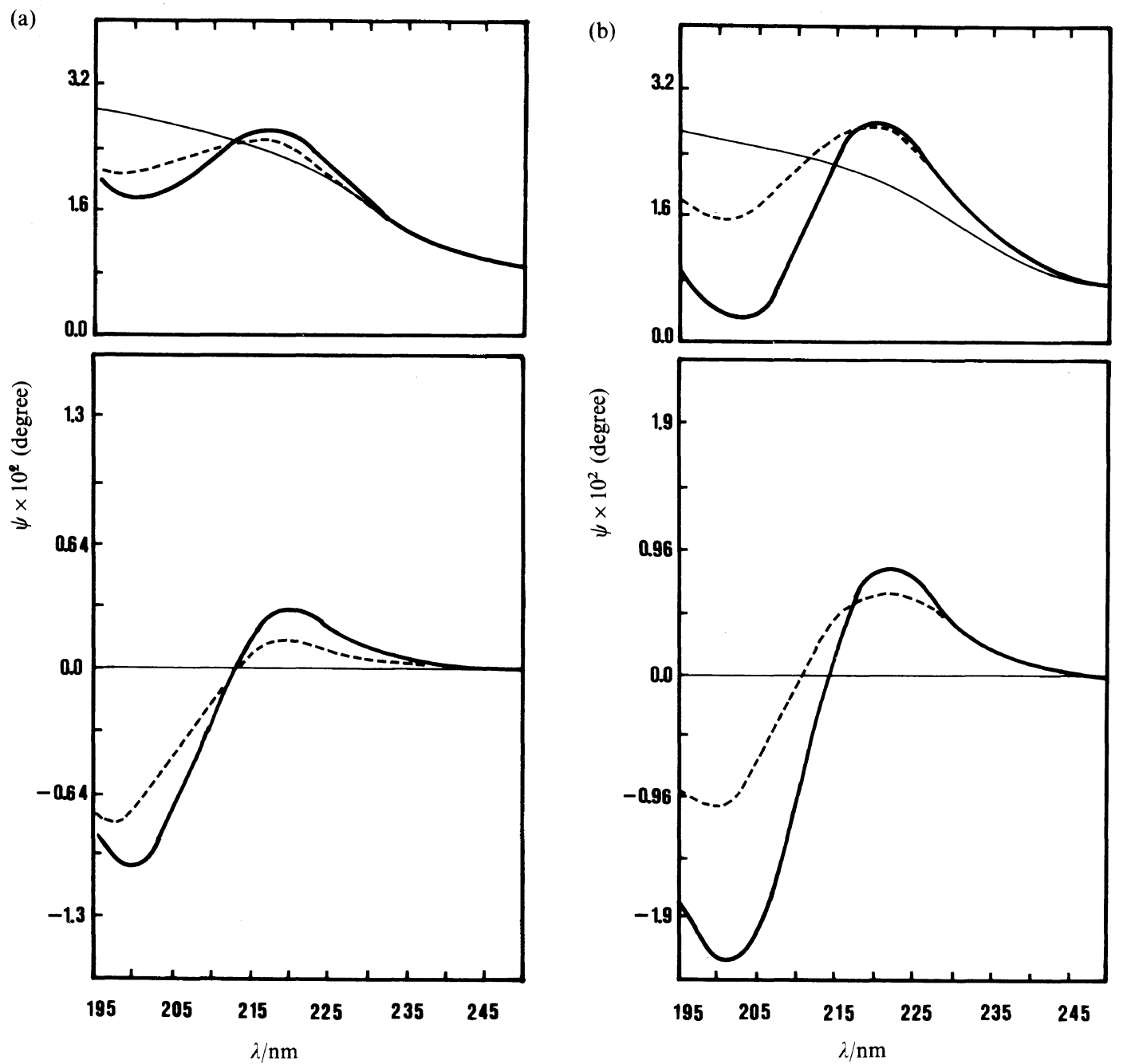

Figure 2. (a): Circular dichroism spectra of the complex system in aqueous solutions at different $\mathrm{Cu}$ (II) /( $\left(-\mathrm{PAAA}_{1}\right)$ molar ratios $(---, 1 / 2 ;-, 1 / 1)$ and at $\mathrm{pH} 2.1$. (b): Same system at pH 4.2 [top, smoothed experimental curves (include solvent); bottom, solvent subtracted spectra].

PAAA $_{2}$ ligands.

Circular Dichroism measurements showed a strong dichroic signal in the UV-range (Figure 2) providing further information on the $\mathrm{Cu}(\mathrm{II}) /\left(l-\mathrm{PAAA}_{1}\right)$ system. Unlike for the protonation mechanism, ${ }^{7}\left[\mathrm{Cu}\left(l \text {-PAAA } A_{1}\right)\right]^{+}$complex formation did not show any conformational transition at a specific $\mathrm{pH}$ value, even in the coil form. This was supported by viscometric data, since no significant viscosity changes were observed over the whole $\mathrm{pH}$ - range before precipitation. The $\mathrm{CD}$ pattern was typical of polypeptides in a random coil conformation $^{13}$ with a positive Cotton effect near $220 \mathrm{~nm}$ and a negative one at $202 \mathrm{~nm}$. The ellipticity was found to increase with $\mathrm{pH}$ and with $\mathrm{Cu}(\mathrm{II}) / \mathrm{L}$ molar ratios. Both effects reflected an increase in the quantity of $\mathrm{Cu}(\mathrm{II})$ complex species which involved the $\mathrm{C}=\mathrm{O}$ group. The molar ellipticity, $[\theta]$, increased with the quantity of $\mathrm{Cu}(\mathrm{II})$ until the $\mathrm{Cu}(\mathrm{II}) / \mathrm{L}$ molar ratio approached one. An example of the 


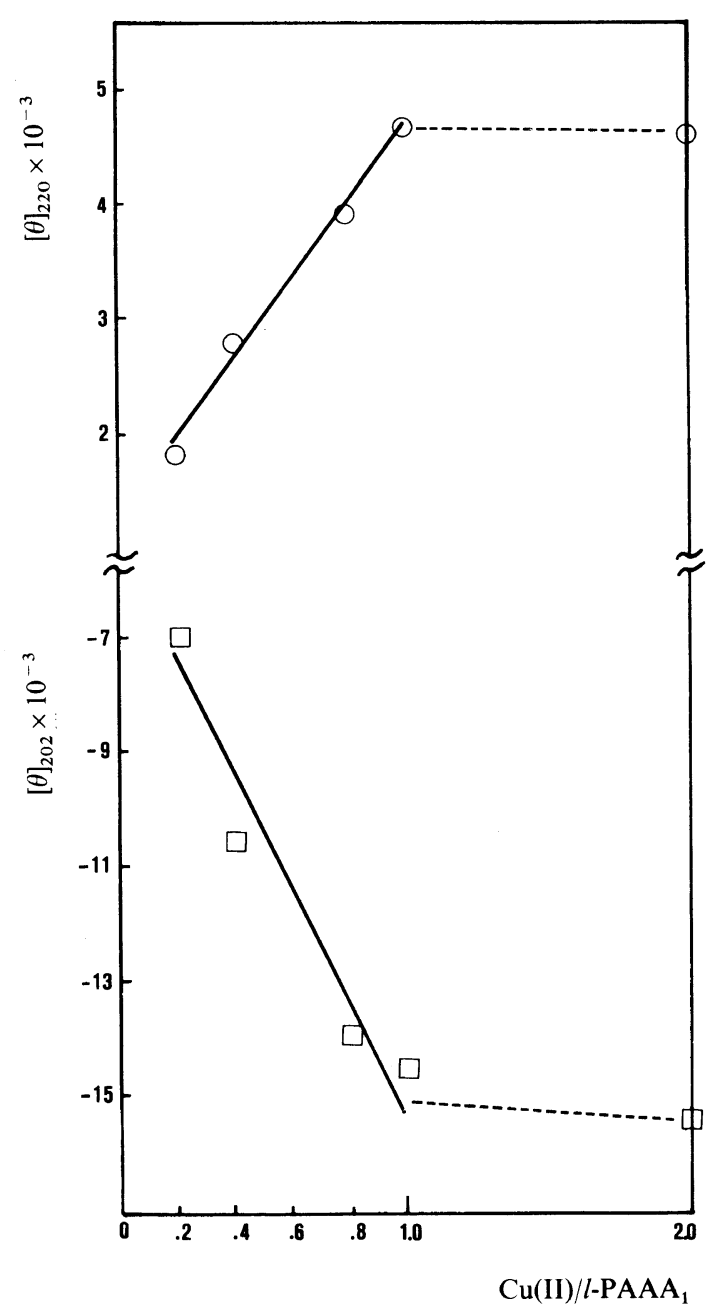

Figure 3. Molar ellipticity values $[\theta]$, at two different wavelengths for the complex system in aqueous solution versus $\mathrm{Cu}(\mathrm{II}) /\left(l\right.$-PAAA $\left.{ }_{1}\right)$ molar ratios at $\mathrm{pH} 3.5$.

linear relationship of $[\theta]$ at 202 and $220 \mathrm{~nm}$, against $\mathrm{Cu}(\mathrm{II}) / \mathrm{L}$ molar ratios at $\mathrm{pH} 3.5$ is plotted in Figure 3. The [ $\theta]$ values at $202 \mathrm{~nm}$ were negative and larger than the positive values of $[\theta]$ at $220 \mathrm{~nm}$. Beyond the $\mathrm{Cu}(\mathrm{II}) / \mathrm{L}$ ratio of $1: 1$, the molar ellipticities remained constant even with a large excess of copper(II) ions. Thus saturation was reached when only one $\mathrm{Cu}(\mathrm{II})$ was bound for each monomer unit.

Further evidence of the types of the coordination sites was revealed by the FT-IR spectrum in solution, obtained at $\mathrm{pH} 3.6$ with a large excess of copper(II) ions. The FT-IR spectrum of the $\left[\mathrm{Cu}\left(l-\mathrm{PAAA}_{1}\right)\right]^{+}$complex species showed two strong bands at 1632 and $1582 \mathrm{~cm}^{-1}$ (Figure 4 and Table III). The disappearance of the band at $1715 \mathrm{~cm}^{-1}$, assigned to the $\mathrm{C}=\mathrm{O}$ stretching of the protonated $\mathrm{COOH}$, confirmed that this group was deprotonated in the presence of metal ions, as occurs in the case of simple amino acids ${ }^{14}$ and polypeptides. ${ }^{15}$

On the basis of this spectroscopic information, different stoichiometries were tested for the evaluation of the stability constant $(\log \beta)$, but only the $\mathrm{CuL}^{+}$complex species was found satisfactory. The $\log \beta$ for each point of the potentiometric titration curve was calculated, taking into account the dependence of the basicity constants on $\mathrm{pH}$ via the Henderson-Hasselbalch equation. ${ }^{2}$ The previously described "Superfit" program refines the $\log \beta$ corresponding to the $\mathrm{CuL}^{+}$complex species in a wide $\mathrm{pH}$-range and with different $\mathrm{Cu}(\mathrm{II}) / \mathrm{L}$ molar ratios. The $\log \beta$ value did not seem to be $\mathrm{pH}$-dependent (Figure 5) unlike in the related $\mathrm{PAAA}_{n}$ polymeric systems considered so far, even if in both cases the basicity constants are very similar in behavior and $\mathrm{pH}$ dependent. ${ }^{7}$ Both PAAA 1 and PAAA 2 polymers showed a high polyelectrolyte effect towards the copper(II) ion because $\log \beta$ evaluated for the simple $\mathrm{CuL}^{+}$species was found to decrease sharply with increasing $\mathrm{pH}$. A comparable decreasing trend was not observed in the $\left.\mathrm{Cu}(l \text {-PAAA })_{1}\right)^{+}$system, $\log \beta$ being almost constant except for a slight step in the vicinity of $\mathrm{pH}$ 3.6. This happened for all three $\mathrm{Cu}(\mathrm{II}) / \mathrm{L}$ molar ratios investigated. Despite the many experimental techniques employed to clarify the $\mathrm{Cu}(\mathrm{II})$ complex formation process, it is not easy to explain this point. Further investigation and comparison of new related polymeric systems is planned. Calorimetric investigation showed "real" enthalpy change values over the whole range of complex formation (Table IV). ${ }^{6}$ The $-\Delta H^{\circ}$ was found to be insensitive to $\mathrm{pH}$ as in the protonation process. $^{7}$ Moreover the $-\Delta H^{\circ}$ value was high- 
$\mathrm{Cu}$ (II) Complex Formation with AA Poly(amido) Polymer Containing $\alpha$-Alanine Residues

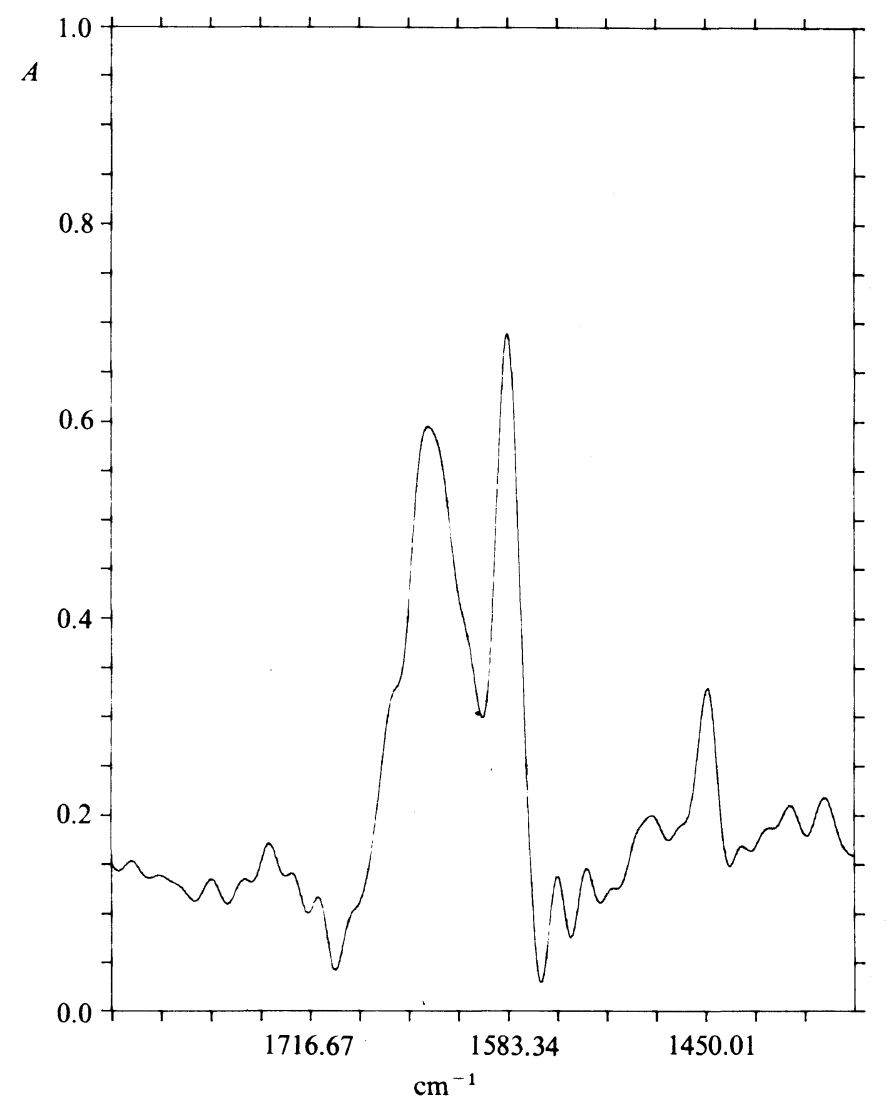

Figure 4. FT-IR difference spectrum of $\left[\mathrm{Cu}\left(l-\mathrm{PAAA}_{1}\right)^{+}\right]$in aqueous solution at $\mathrm{pH} 3.6$.

Table III. FT-IR frequencies for the Cu(II)/l-PAAA $1, l$-PAAA ${ }_{1}$, and $\mathrm{Cu}(\mathrm{II}) / \mathrm{PAAA}_{1}$ systems in aqueous solution ${ }^{\mathrm{a}}$

\begin{tabular}{|c|c|c|c|c|c|}
\hline \multirow{2}{*}{ Species } & \multirow{2}{*}{$\mathrm{pH}$} & \multicolumn{3}{|c|}{ Stretching frequencies $\left(\mathrm{cm}^{-1}\right)$} & \multirow{2}{*}{ Ref } \\
\hline & & $\mathrm{N}-\mathrm{C}=\mathrm{O}$ & $\mathrm{COO}^{-\mathrm{a}}$ & $\mathrm{COO}^{-\mathrm{b}}$ & \\
\hline$l$-PAAA 1 & 11.5 & $1675 \mathrm{~m}$ & $1596 \mathrm{~s}$ & $1405 \mathrm{~m}$ & 7 \\
\hline$\left[\mathrm{Cu}\left(l-\mathrm{PAAA}_{1}\right)\right]^{+}$ & 3.6 & $\begin{array}{l}1632 \mathrm{~s} \\
1657 \mathrm{sh}\end{array}$ & $1582 \mathrm{~s}$ & $1395 \mathrm{~m}$ & This paper \\
\hline$\left[\mathrm{Cu}\left(\mathbf{P A A A}_{1}\right)\right]^{+}$ & 1.8 & $1630 \mathrm{~s}$ & 1582 vs & $1390^{\circ} \mathrm{m}$ & 6 \\
\hline
\end{tabular}

$\mathrm{vs}=$ very strong, $\mathrm{s}=$ strong, $\mathrm{m}=$ medium, $\mathrm{sh}=$ shoulder.

a Antisymmetric stretching.

b Symmetric stretching.

er than the corresponding complex species of simple $\alpha$-alanine ${ }^{16}$ confirming once more the participation of the $\mathrm{C}=\mathrm{O}$ groups in coordination with the metal ion. This was already hypothesized for previously studied related polymers having geometry consistent with an octahedral tetragonally-distorted structure.

\section{DISCUSSION}

Investigation of the $\mathrm{Cu}$ (II) complex formation process previously revealed that 


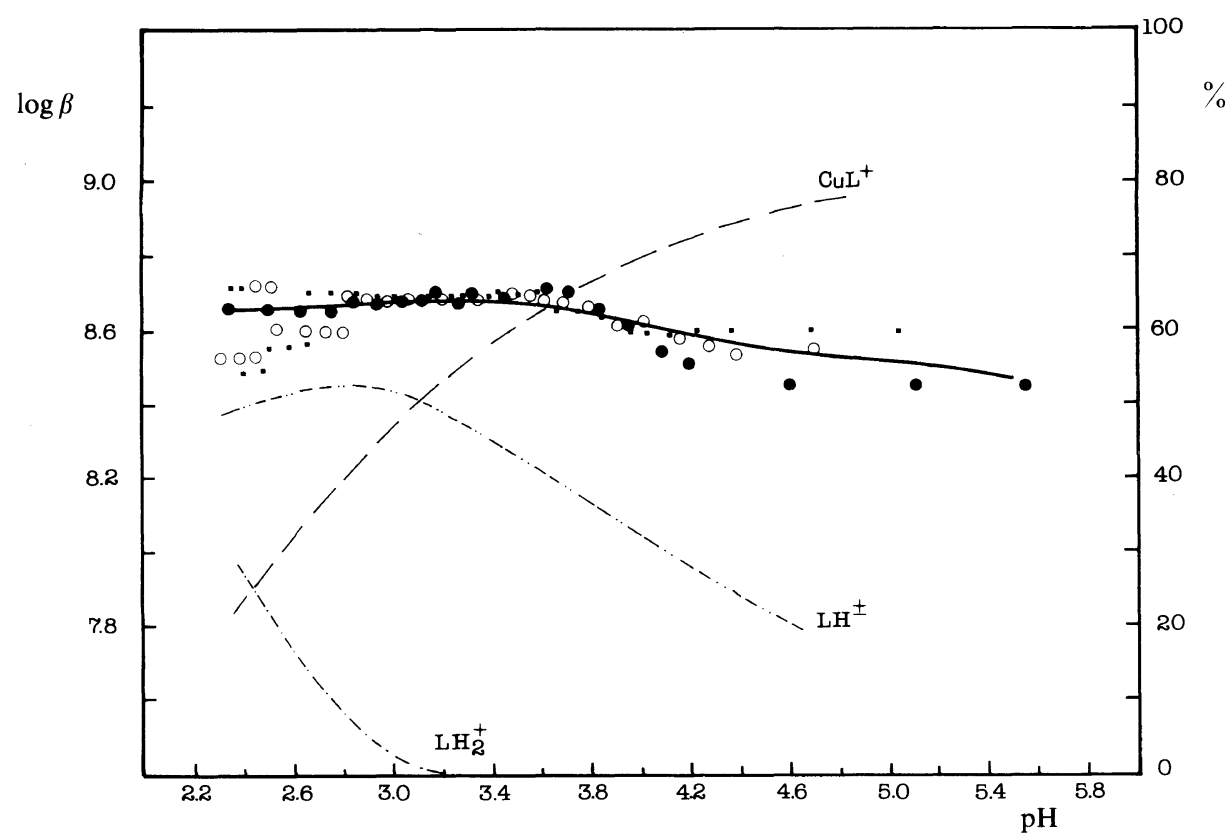

Figure 5. Variation of the $\left[\mathrm{Cu}\left(l-\mathrm{PAAA}_{1}\right)\right]^{+}$stability constant $(\log \beta)$ versus $\mathrm{pH}$ at different $(\bigcirc, 1 / 0.8 ; \square$ $1 / 0.6 ; 0,1 / 0.5)$ polymer/Cu(II) molar ratios. Dotted lines are the distribution curves of the protonated and complexed species at $1 / 0.8$ polymer $/ \mathrm{Cu}(\mathrm{II})$ molar ratio.

Table IV. Thermodynamic results for the copper(II) complexes of $l$-PAAA 1 and related PAAA polymers at $25^{\circ} \mathrm{C}$ in $0.1 \mathrm{M} \mathrm{NaCl}$

Reaction: $\mathrm{Cu}^{2+}+\mathrm{L} \rightleftharpoons \mathrm{CuL}^{+}, \mathrm{L}$ is the anionic monomer unit.

\begin{tabular}{|c|c|c|c|c|c|}
\hline Complex species & pH-range & $-\Delta G^{\circ \mathrm{a}} / \mathrm{kcal} \mathrm{mol}^{-1}$ & $-\Delta H^{\circ \mathrm{a}} / \mathrm{kcal} \mathrm{mol}^{-1}$ & $\Delta S^{\circ \mathrm{a}} / \mathrm{cal} \mathrm{mol}^{-1} \mathrm{~K}^{-1}$ & Ref \\
\hline $\mathrm{Cu}\left(l \text {-PAAA }{ }_{1}\right)^{+}$ & $2.3-5.4$ & 11.7 & $5.9(5)$ & $20(2)$ & This paper \\
\hline $\mathrm{Cu}\left(\mathrm{PAAA}_{1}\right)^{+}$ & $2.2-4.5$ & $12.3-11.3$ & 7.2 & $17.1-13.8$ & 2,6 \\
\hline $\mathrm{Cu}\left(\mathrm{PAAA}_{2}\right)^{+}$ & $4.0-6.5$ & $9.1-7.9$ & 3.8 & $17.8-13.8$ & 2,6 \\
\hline $\mathrm{Cu}(\alpha \text {-ala })^{+}$ & $3.2-6.6$ & $11.12(1)$ & $5.6 \pm 0.15$ & $18.5 \pm 0.5$ & 16 \\
\hline
\end{tabular}

${ }^{a}$ Values in parentheses are standard deviations. $l$-PAAA $1=$ poly $($ amino- $\alpha$-alanine $)$ PAAA PA $_{1}=$ poly(amido-glycine); PAAA $_{2}=$ poly $($ amido- $\beta$-alanine $) ; \alpha$-ala ${ }^{-}=\alpha$-alaninate ${ }^{-}$.

poly(amido) polymers with glycine and $\beta$ alanine residues coordinate the metal ion with an octahedral tetragonally-distorted geometry similar to the classical poly(amido amine)s of $\mathrm{CuL}^{2+}$ stoichiometry. However the behavior of $\mathrm{Cu}(l \text {-PAAA })^{+}$was different not only as revealed by spectroscopic analysis but also in complexation thermodynamics. The high molar absorption coefficient $(\varepsilon)$ and the lower values of $g_{\|}$and $A_{\|}$were the main spectroscopic differences from the other complexes of similar stoichiometry (Table II). The differ- ences in the ligand structure lead to greater distortion with a stronger axial field than in homologous complex species, since the lower value of $A_{\|}$is compatible with a decreased field in the equatorial plane. ${ }^{6}$ The presence of the methyl group in the $\alpha$-alanine residue can be expected to affect the electronic spectra in two ways. ${ }^{17}$ Firstly, steric hindrance of the methyl group could lead to a change in geometric symmetry. The steric hindrance could be relieved by a movement of the $\mathrm{Cu}$ (II) back into the equatorial plane and this would probably 
be accompanied by a slight increase in the axial bond length. The second effect expected to follow from the presence of the methyl group is an increase in the polarizability of the $\mathrm{N}$-donor atom leading to larger value of $\varepsilon$ because of increased covalency in the $\mathrm{Cu}-\mathrm{N}$ bonds. Such an increase in the $\varepsilon$ value was in fact observed. The spectral shift to shorter $\lambda_{\text {max }}$ then corresponds to an increase in the ligand field as donor oxygen atoms of water molecules are replaced by the adjacent carbonyl groups. These groups are known to participate in symmetrically substituted tertiary diamines in poly(amido amine)s $\left(\mathrm{N}_{2}\right)^{9,18}$ :

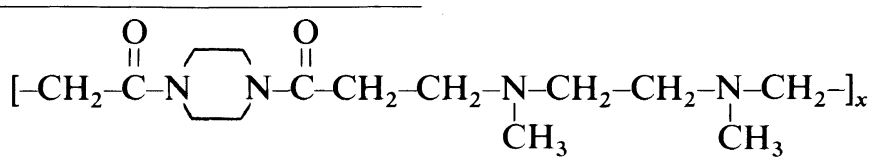

Further, a slight blue shift was observed in symmetric $\left[\mathrm{Cu}(\mathrm{II})-\mathrm{N}_{2}\right]^{2+}$ complex species with respect to unsymmetrically substituted analogues $\left(\mathrm{N}_{2} \mathrm{P}\right)^{18}$.<smiles>CN(C)CCN(CI)CCC(=O)N1CCN(C(=O)CI)CC1</smiles>

The positive peak at $220 \mathrm{~nm}$, assigned to the $n-\pi^{*}$ amide transition, and the intense negative one near $202 \mathrm{~nm}$, assigned to the $\pi-\pi^{*}$ transition, can be attributed to a charge-transfer transition ${ }^{19,20} \mathrm{COO}^{-} \rightarrow \mathrm{Cu}$ in the complex system and turns out to be higher than that found in the protonation process, ${ }^{7}$ which involves the same interaction of the amide $\mathrm{C}=\mathrm{O}$ groups with the protonated tertiary nitrogen in a closed ring with the $\mathrm{COO}^{-}$group. From the analysis of the IR frequencies the band at $1582 \mathrm{~cm}^{-1}$ can be assigned to the antisymmetric stretching of the coordinated $\mathrm{COO}^{-} .^{6,14}$ As a matter of fact this value was lower than that found in the spectrum of the free ligand at high $\mathrm{pH}$ values (Table III). The band at $1632 \mathrm{~cm}^{-1}$ has been assigned to the stretching of the amidic $\mathrm{C}=\mathrm{O}$ group. ${ }^{6}$ This band is not a pure band as in the case of PAAA $_{1}{ }^{6}$; in fact in the spectrum of $[\mathrm{Cu}(l-$ $\left.\mathrm{PAAA}_{1}\right)^{+}$a shoulder also appeared at $1657 \mathrm{~cm}^{-1}$. Both these bands (1632 and
$1657 \mathrm{~cm}^{-1}$ ) occurred at lower frequencies than that of the free amidic $\mathrm{C}=\mathrm{O}$ present at $1675 \mathrm{~cm}^{-1}$ in the spectrum of the free ligand in aqueous solution ${ }^{7}$ (Table III). This may be interpreted as due to the presence of two amidic $\mathrm{C}=\mathrm{O}$ groups differently coordinated to the copper(II) ion.

The mean $-\Delta G^{\circ}$ free energy value (Table IV) is higher than for the corresponding complex obtained with simple $\alpha$-alanine ${ }^{21}$ but, roughly speaking, resembles the mean value of $-\Delta G^{\circ}$ for $\left[\mathrm{Cu}\left(\mathrm{PAAA}_{1}\right)\right]^{+}$which decreases regularly with $\mathrm{pH}$ (Table IV). The methyl group in $l$-PAAA ${ }_{1}$ affects the symmetry of the monomeric unit once coordinated and determines a more hydrophobic microenvironment which affects the cooperativity between monomeric units of the same macromolecule. As stated elsewhere, the trend of $\log \beta v s . \mathrm{pH}$ is decreasing for complex reactions with partial or full neutralization of charges. ${ }^{4}$ The present complex system seems to be comparable to the protonation behavior when hydrophobicity affects polyelectrolyte character ${ }^{22}$; the higher the hydrophobicity, the lower the polyelectrolyte effect in the protonation reaction. ${ }^{2,23}$ The presence of the methyl group only influences the magnitude of the calorimetric data; this is due to inductive effect. The $-\Delta H^{\circ}$. value, in fact, is lower than for the $\mathrm{Cu}\left(\mathrm{PAAA}_{1}\right)^{+}$complex but resembles the value found for simple $\mathrm{Cu}$ (II)$\alpha$-alanine and does not change with $\mathrm{pH}$. Accordingly the $\Delta S^{\circ}$ value (Table IV) is comparatively greater. This suggests that the geo- 
metry of the complex formed may be different and involve a decrease in the coordination number because of the further loss of water molecules from the coordination sphere of the metal ion.

\section{CONCLUSIONS}

The above experimental data for the $[\mathrm{Cu}(l-$ PAAA $\left.A_{1}\right]^{+}$complex species is compatible with the following square-pyramidal structure:

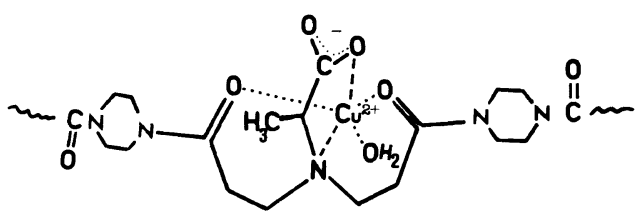

This structure involves:

1) the coordination of the amino acid moiety, the two $\mathrm{C}=\mathrm{O}$ groups on both sides, which may be differently coordinated, and one water molecule;

2) the thermodynamic changes are influenced by the hydrophobic methyl group, determining a diminishing effect on the trend of $\log \beta$ vs. $\mathrm{pH}$ accompanied by a greater dehydration process.

The above structure is different from that of the previously studied complexes with glycine and $\beta$-alanine residues in poly(amido) polymers for which both spectroscopic and thermodynamic data were consistent with an octahedral tetragonally-distorted $\left[\mathrm{Cu}\left(\mathrm{PAAA}_{n}\right)\right]^{+}$ complex. $^{6}$

Acknowledgements. This work was financially supported by the Italian Ministry of Education. One of the authors (M.C.) wishes to express his sincere gratitude to Prof. Masahiko Sisido (Tokyo Institute of Technology) for the helpful discussion of the CD results and continuous encouragement during his stay at Kyoto University, Japan. Thanks are due to Dr. Franco Laschi (Department of Chemistry, University of Siena) for recording the ESR spectra.

\section{REFERENCES AND NOTES}

1. P. Ferruti and R. Barbucci, Adv. Polym. Sci., 58, 57 (1984).

2. R. Barbucci, M. Casolaro, M. Nocentini, S. Corezzi, P. Ferruti, and V. Barone, Macromolecules, 19, 37 (1986).

3. M. Casolaro, M. Nocentini, and G. Reginato, Polym. Commun., 27, 14 (1986).

4. R. Barbucci, M. Casolaro, S. Corezzi, and G. Reginato, Polymer, 27, 1986 (1986).

5. J. A. Marinsky, Coord. Chem. Rev., 19, 125 (1976).

6. R. Barbucci, M. J. M. Campbell, M. Casolaro, M. Nocentini, G. Reginato, and P. Ferruti, J. Chem. Soc., Dalton Trans., 2325 (1986).

7. R. Barbucci, M. Casolaro, A. Di Tommaso, and A. Magnani, Macromolecules, 22, 3138 (1989).

8. F. Danusso and P. Ferruti, Polymer, 11, 88 (1970).

9. R. Barbucci, M. Casolaro, V. Barone, P. Ferruti, and M. Tramontini, Macromolecules, 16, 1159 (1983).

10. J. H. Venable, Ph. D. Thesis, Yale University (1965). Available on microfilm from University Microfilm Inc. Ann Arbor, Michigan, U.S.A., order no. 66-117.

11. R. Tanaka, in "Data acquisition and processing for Jasco J-500," MS-DOS version (1986), available on floppy disk from M. Sisido, Tokyo Institute of Technology.

12. K. Nakamoto and P. J. McCarthy, in "Spectroscopic and Structure of Metal Chelate Compounds," John Wiley \& Sons, Inc., New York, N. Y., 1968.

13. G. Holzwarth and P. Doty, J. Am. Chem. Soc., 87, 218 (1965).

14. K. Nakamoto, Y. Narimoto, and A. E. Martell, $J$. Am. Chem. Soc., 83, 4528 (1961).

15. a) M. K. Kim and A. E. Martell, J. Am. Chem. Soc., 88, 914 (1966).

b) M. Tasumi, S. Takahashi, T. Nakata, and T. Miyazawa, Bull. Chem. Soc. Jpn., 48, 1595 (1975).

16. T. Po I and G. H. Nancollas, Inorg. Chem., 11, 2414 (1972).

17. R. Barbucci, A. Mastroianni, and M. J. M. Campbell, Inorg. Chim. Acta, 27, 109 (1978).

18. R. Barbucci, M. Casolaro, P. Ferruti, and V. Barone, Polymer, 23, 148 (1982).

19. S. Beychok, in "Poly- $\alpha$-amino acids," G. D. Fasman, Ed., Marcel Dekker, New York, N. Y., 1967.

20. E. W. Wilson, Jr., M. H. Kasperian, and B. Martin, J. Am. Chem. Soc., 92, 5365 (1970).

21. A. E. Martell and R. M. Smith, in "Critical Stability Constants: Amino acids," Vol. 1, Plenum Press, New York, N. Y., 1974

22. R. Barbucci, M. Casolaro, P. Ferruti, M. C. Tanzi, L. Grassi, and C. Barozzi, Makromol. Chem., 185, 1525 (1984).

23. R. Barbucci, M. Casolaro, and A. Magnani, Makromol. Chem., in press (1989). 